IRA-International Journal of Management \&

Social Sciences

ISSN 2455-2267; Vol.12, Issue 03 (September 2018)

Pg. no. 62-72.

Institute of Research Advances

http://research-advances.org/index.php/RAJMSS

\title{
Accuracy of References in Journal Literature of Medical Sciences: A Review
}

\author{
Vishnu Kumar Gupta ${ }^{1 \#}$ \& Dr. Praveen Babel ${ }^{2}$ \\ ${ }^{1}$ Assistant Professor, Department of Library and Information Science, University of Rajasthan, \\ Jaipur (Rajasthan)- INDIA 302004 \\ 2Librarian, WISDOM, Faculty of Management Studies, Banasthali University, Banasthali \\ (Rajasthan)- INDIA 304022.
}

" corresponding author.

Type of Review: Peer Reviewed.

DOl: http://dx.doi.org/10.21013/jmss.v12.n3.p2

\begin{abstract}
Gupta, V.K., Babel, P. (2018). Accuracy of References in Journal Literature of Medical Sciences: A Review. IRA-International Journal of Management \& Social Sciences (ISSN 2455-2267), 12(3), 62-72. doi:http://dx.doi.org/10.21013/jmss.v12.n3.p2
\end{abstract}

(C) Institute of Research Advances.

\section{(c)) EY-NC}

This work is licensed under a Creative Commons Attribution-Non Commercial 4.0 International License subject to proper citation to the publication source of the work.

Disclaimer: The scholarly papers as reviewed and published by the Institute of Research Advances (IRA) are the views and opinions of their respective authors and are not the views or opinions of the IRA. The IRA disclaims of any harm or loss caused due to the published content to any party.

Institute of Research Advances is an institutional publisher member of Publishers International Linking Association Inc. (PILA-CrossRef), USA. The institute is an institutional signatory to the Budapest Open Access Initiative, Hungary advocating the open access of scientific and scholarly knowledge. The Institute is a registered content provider under Open Access Initiative Protocol for Metadata Harvesting (OAI-PMH).

The journal is indexed \& included in WorldCat Discovery Service (USA), CrossRef Metadata Search (USA), WorldCat (USA), OCLC (USA), Open J-Gate (India), EZB (Germany) Scilit (Switzerland), Airiti (China), Bielefeld Academic Search Engine (BASE) of Bielefeld University, Germany, PKP Index of Simon Fraser University, Canada. 


\begin{abstract}
This review of literature presents the accuracy level of references in journal articles related to domain of medical science and its allied subjects. Peer-reviewed journals, which are being indexed in international citation databases and possess high impact factor, have reference errors. Not only journal articles but also the PubMed database contains bibliographic errors. Due to faulty references, task of indexing and abstracting of authors and articles in citation databases becomes troublesome. The high level of reference accuracy makes the scientific writings more reliable and useful which further moves towards the high quality scholarship.
\end{abstract}

Keywords- Reference Accuracy, Citation Errors, Journal Literature, Medical Literature, Scholarly Communication.

\title{
1. Background
}

Doctors, medical scientists and research scholars share and/or communicate research results to audiences in formal channels of communication in the format of journal articles, books, conference proceedings, etc. According to Borgman (1990), scholarly communication is concerned with "using and disseminating information in academic fields through formal and informal channels."1

A list of references appears in every scholarly writings in the format of journal article, book, and conference proceedings. List of references is an essential and inevitable part of a scientific paper ${ }^{2}$ (Gupta, 2018). The list of references allows the readers to access the concerned information sources on the specific subject domain of the paper in order to acquire further and detailed information when needed. Such lists are also known as "References cited." These references indicate towards original documents related to the theme or topic of the scientific article.

Inaccuracies in article reference lists create problems in various subject fields in research as mentioned by Idrisa Pandit ${ }^{3}$ in 1993. Alfred Yankauer (1990) defined citation error as, "errors of commission or omission in the printing of the reference"4 (p. 38). C. A. Doms (1989) also explained and precisely defined a correct reference, or an accurate reference as "one in which all included elements are identical to the source", (p. 442). Faulty and inaccurate references create distrust on the trustworthiness and capability of the researcher. The only way to give assurance of reference accuracy in articles is to cross check and verify each and every reference appended in article from the original information sources. Maintaining the top level accuracy in citations is one of the good qualities of an author ${ }^{6}$ (Gupta, 2017a). The accurate and exact compiling of references is critical in all varieties of scientific writings. Faulty and erroneous references may have critical consequences, like as impeding the searching and retrieving of $\operatorname{articles}^{7}$ (Spivey \& Wilks, 2004), creating disbeliefs about the credibility of authors and researchers ${ }^{8}$ (Faunce \& Job, 2001), and showing badly on the publishing journals ${ }^{9}$ (Onwuegbuzie, Frels, \& Slate, 2010).

It is critically important to clearly define the role and tasks of all key stakeholders of scientific communication for monitoring and controlling the problems of irrational and unethical references. With the phenomenal growth and uncontrolled development of literary items and related references, it is a challengeable function of scientific community to increase the quality and indexability of scholarly writings, especially in journal's $\operatorname{articles}^{10}$ (Gasparyan et al., 2015).

A list of references in a scientific article provides detailed background of information sources consulted and used directly or indirectly during the study, and indicates that the researcher has researched the paper's theme thoroughly. The present review encapsulates significant research studies on reference accuracy and citation error in medical science and its allied fields in a systematic way by classifying them into several subcategories.

\section{Medical Science Literature}

Scientific articles appeared in medical science journals contain a list of references, which provides link of information sources to the users. Assertions and interpretations in the article are also verified with the help of the cited references. Errors in references may make it hard for the user in retrieving references and verifying information to which the text of an article refers.

Goodrich and Roland ${ }^{11}$ (1977), in their signature study, found that "among 2,195 reference citations published during 1975 in 10 major U.S. medical journals, 634 (29\%) were found to be erroneous on direct checking of the original source." This work is considered as the earliest research in the reference accuracy field. 
In 1985, De Lacey, Record, and Wade ${ }^{12}$ conducted a research on accuracy of references, including quotations in six journals of medical science. They found the $24 \%$ inaccurate references, and of those, $8 \%$ contained major errors.

Evans, Nadjari, and Burchell ${ }^{13}$ (1990) investigated 150 randomly selected references cited in three medical science periodicals and found $48 \%$ error rate. Ngan Kee, Roach, and Lau ${ }^{14}$ (1997a) reviewed and examined the references appended in all eight issues in the volume 1 and 2 of the "Hong Kong Medical Journal" published in 1995 and 1996 to measure their accuracy. A total of 100 cited references were randomly chosen from each volume. After excluding all cited references not from indexed journals in Index Medicus, all references were checked in detail by splitting them into six elementary bibliographic components and matching them from the original sources. They revealed that " $61 \%$ of references in volume 1 and $51 \%$ of references in volume 2 contained inaccuracies, giving an overall error rate of 56\%" (p. 377). Nearly $38 \%$ of cited references consisted errors in one component, $16 \%$ consisted errors in two components, and $2 \%$ consisted errors in three or more components. The most common errors detected in the title and authors' names. The citation error rate in the "Hong Kong Medical Journal" is very high while comparing with other reference accuracy studies of medical science journals.

Prakash Adhikari ${ }^{15}$ (2009) conducted a research to check the accuracy of 30 randomly selected references in papers published in three indexed journals in Nepal published during January 2007 to December 2008, namely- "Journal of Nepal Medical Association" (JNMA), "Kathmandu University Medical Journal" (KUMJ), and "Nepal Medical College Journal" (NMCJ). By splitting up references into 6 components, they were verified pin-pointedly, and compared with the original sources for accuracy. The references, which cited in the indexing journals, were considered for verification. Findings revealed that $11.6 \%, 11.1 \%$ and $23.3 \%$ references in NMCJ, JNMA, and KUMJ were inaccurate, respectively.

Samad, Khanzada, Kumar, \& Malik ${ }^{16}$ (2013) examined and compared the errors in 200 references (100 each journal) appended in articles in two prominent medical journals, entitled the "Journal of Pakistan Medical Association" and the "Journal of the College of Physicians and Surgeons" published from Pakistan in 2008. Only $9.5 \%$ (19) articles were detected error free.

In December 2017, the "International Committee of Medical Journal Editors" (ICMJE) recently issued an updated version of recommendations, entitled "Recommendations for the Conduct, Reporting, Editing, and Publication of Scholarly Work in Medical Journals." 17 The ICMJE focused the need of citing primary information sources and neglecting unethical citations, which are acceptable to the global academic and scientific community.

\subsection{Public Health Literature}

From the May 1986 issue of each of three public health periodicals, choosing a random sample of 50 references, Eichorn and Yankauer ${ }^{18}$ (1987) observed that $31 \%$ references were erroneous. In this study, minor omissions in author names or article title and misspellings were the most common citation errors. References of journals not in the medical school library and non-English language journals, along with all non-journal references (books, conference papers, government publications, etc.) were noted down but not considered in the 150 references.

\subsection{Physical Medicine and Rehabilitation Literature}

Few journal publications, for example the "Archives of Physical Medicine and Rehabilitation," have hired review professionals to examine the correctness of bibliographical references in papers that they received for publications. Two such professionals named Key and Roland ${ }^{19}$ (1977) checked the references of 129 papers submitted for publication to the "Archives of Physical Medicine and Rehabilitation" and concluded that "54\% of the 1,867 references examined were incorrect, and $6 \%$ could not be verified." They did not further analyze the same 129 papers after they were published.

\subsection{Dental Journals}

C. A. Doms ${ }^{5}$ (1989) revealed that " $42 \%$ of references in dental journals were inaccurate." Thirty percent of these were major errors, for example as authors name, incorrect article titles, and/or journal titles. Doms verified a total of 500 references, randomly selected from March 1987 issue of each of five dental journals. One hundred references were taken from each journal. All bibliographic elements of each reference were examined from the original documents and indexing sources. All the references were classified into two 
groups: correct and incorrect. The quantity of incorrect references was evaluated and further sub-classified into minor and major errors.

\subsection{Emergency Medicine Literature}

Goldberg et al. ${ }^{20}$ (1993) determined the nature and incidence of errors in the reference and quotation of references consisted in the emergency medicine journals. They checked single issues of three journals of emergency medicine, viz. “American Journal of Emergency Medicine," “Annals of Emergency Medicine," and "Journal of Emergency Medicine." Four external reviewers examined 145 citations from 46 citing authors for the accuracy of citation and quotation. Major and minor reference errors were detected in $10.3 \%$ and $17.2 \%$ of reference lists, respectively. Qualitative quotation errors were detected in $35.2 \%$ of references. $82 \%$ of these errors were considered to be major.

The accuracy of reference of all 2724 references contained in 254 articles appeared in "Emergency Medicine Journal" in the year 2003 by using authentic print and electronic sources was carefully determined by Raja and Cooper ${ }^{21}$ in 2006. Raja and Cooper (2006) concluded that "citation errors reflect badly on authors and the publishing journal and may reflect underlying flaws in other areas of the research published."21 They further hoped that "identification of this problem will lead to attempts to improve the accuracy of reference citation in the emergency medicine literature and to an improvement in the credibility of research in our specialty" ${ }^{21}$ (Raja \& Cooper, 2006, p. 625).

O'Connor, Lukin, Eriksson, and O'Connor ${ }^{22}$ (2013) analysed the accuracy of references appended in Volume 22 of "Emergency Medicine Australasia" and compared the results with the volume 12. They further demonstrated an important betterment in the level of accuracy of references in the "Emergency Medicine Australasia" journal. They listed and numbered all citations appended in Vol. 22 of "Emergency Medicine Australasia." By using the random number generator facility of Microsoft Excel 2000, a sample of 100 references was chosen. This method was selected to allow a direct comparison of the findings of this analysis with an identical analysis of the references in Vol. 12 of the journal (earlier entitles as "Emergency Medicine"). The size of sample was selected to compare the review of Vol. 12. The earlier study showed 35\% of references contained errors.

\subsection{Dermatology Journals}

George and Robbins ${ }^{23}$ (1994) tried to determine the reference accuracy in the dermatologic journals. They randomly chosen 240 references (60 references from one journal) from the four journals, namely: "Archives of Dermatology," "British Journal of Dermatology," "Journal of the American Academy of Dermatology," and "Journal of Investigative Dermatology" and examined them against the original sources. The overall citation error rate was $41 \%$, and the quotation error was $35 \%$. Only $36 \%$ of references were accurate. This work reveals that the citation error rate and quotation error rate are amazingly high in the dermatology journals, which significantly decreases the worth and quality of the references.

Singh and Chaudhary ${ }^{24}$ (2009) analysed 50 references cited in research papers appeared in "Indian Journal of Dermatology, Venereology and Leprology" for their quotation and citation accuracy as an sign of the quality of scholarly articles.

\subsection{Therapy Literature}

Gosling, Cameron, and Gibbons ${ }^{25}$ (2004) investigated the accuracy of references and quotations in four peer-reviewed journals in the field of manual therapy published from Jan. 2000 to Dec. 2001, using a stratified random sample of 80 references from every journal article (Total 320 references). Inaccurate references were calculated and errors among them were categorized as minor and major errors. The errors were traced in following seven bibliographic elements:- author, title, journal, year, volume, page, and irretrievable. Each and every quoted statement was individually examined for accuracy and determined to be either incorrect or correct. A quotation was considered correct if it correctly reported and substantiated the original authors' statements. A total of $115(35.9 \%)$ references among all journals had errors. Some references showed more than one minor and major errors. Errors in bibliographical elements exhibited in author 61, in title 51, in journal 6, in year 4, in volume 12 and in page 25 errors. "Journal of Manipulative and Physiological Therapeutics" (JMPT) presented the $20 \%$ error rate, which was lowest with regards to the other journals. "Journal of Bodywork and Movement Therapies" (JBWMT) showed the $58.8 \%$ error rate, which was the highest. 
Unver, Senduran, Kocak, Gunal, and Karatosun ${ }^{26}$ (2009) examined the frequency of errors in references embedded in four prominent peer-reviewed rehabilitation and physical therapy journals, viz. "American Journal of Physical Medicine and Rehabilitation," "Archives of Physical Medicine and Rehabilitation," "Clinical Rehabilitation," and "Physical Therapy" published during 2003 to 2007. By randomly selecting 100 references from each journal, 400 references were verified from MEDLINE database and original article. One hundred twenty three $(30.7 \%)$ references among all 400 references consisted at least single error and citation error rate varied from $23 \%$ to $44 \%$. Author's name contained highest errors (48\%). Reference errors occur in recent physical therapy and rehabilitation peer-reviewed journals, albeit most are not critical.

\subsection{Biomedical Literature}

A study conducted by Aronsky, Ransom, and Robinson ${ }^{27}$ (2005), in which a total of 656 eligible references (out of total 1356 references) appended in 37 papers from the first issues of five journals in the field of biomedical informatics published in 2004, namely- (in alphabetical order) "Artificial Intelligence in Medicine," "International Journal of Medical Informatics, " “Journal of Biomedical Informatics," "Journal of the American Medical Informatics Association," and "Methods of Information in Medicine" were verified from the Medline database for authors, journals, article's titles, year of publication, volume number, and page number accuracy. If differences were observed, the reference was verified with the original source. Two reviewers separately assessed every reference. The findings show that out of 656 verified references, 225 (34.3\%) references had minimum one error; and among the 225 references, 311 errors were observed.

Various references in biomedical informatics periodicals contain inaccuracies. Erroneous references may reflect badly on the biomedical informatics area and are frustrating. Authors in the area of biomedical informatics should verify and validate the accuracy of references appended in manuscripts by checking with the original paper. The main responsibility of the reference accuracy lies on the feet of authors. Authors should more attentively verify references, by using "informatics-based" assistance ${ }^{27}$ (Aronsky, Ransom, \& Robinson, 2005). Proper and correct compiling of references in scholarly papers is significant to the readers.

\subsection{Anaesthesia Literature}

McLellan, Case, and Barnett ${ }^{28}$ (1992) studied the reference accuracy in anaesthesia literature. The high level of reference accuracy, undoubtedly, makes the scholarly communication more reliable as well as useful, and leads towards the high quality scholarship ${ }^{29}$ (Asano, Mikawa, Nishina, Maekawa, \& Obara, 1995a). The reference errors of the "Canadian Journal of Anaesthesia" were reduced by 50\% from 1990 to 1994 by demanding the xerox or duplicate copy of the starting page of every reference cited in the "Reference lists" (Asano, Mikawa, Nishina, Maekawa, \& Obara, 1995b).

\subsection{Surgery Literature}

Orlin, Pehling, and Pogrel $^{31}$ (1996) conducted an investigation of 500 citations randomly chosen from the issues of the "Journal of Oral and Maxillofacial Surgery" published from January to July 1992. They revealed that $26 \%$ references contained inaccuracies. Six percent of the cited papers cannot be retrieved at all.

Ngan Kee, Roach, and Lau ${ }^{32}$ (1997b) evaluated the accuracy of references in the "Australian and New Zealand Journal of Surgery." They randomly selected a sample of 100 references from the Volume 65 (1995) and verified them in detail with the original sources. They found $60 \%$ of references incorrect. Errors were grouped by splitting up references into six components. A total of 38.8\%, 15.6\%, 4.4\%, and 4.4\% of references had errors in one element, in two elements, in three elements, and in four elements of the reference, respectively.

The aim of Fenton, Brazier, Souza, Hughes, and McShane ${ }^{33}$ (2000) work was to measure the occurrence of errors in quotations and citations in journal literature of otolaryngology/head and neck surgery. A retrospective analysis was conducted on the basis on the first issue of 1997 of each four journals- namely, "Laryngoscope," “Annals of Otology," "Rhinology and Laryngology," “Clinical Otolaryngology," and "Journal of Laryngology and Otology." Fifty references randomly selected from each journal (a total of 200 references) and each reference was examined for accuracy by using the original sources. Citation errors were classified as major, intermediate and minor. Errors in references detected in $37.5 \%$ of the cited references, $11.9 \%$ of which were observed as major errors.

By randomly selecting the 100 references from both of the 1985 and 1995 volumes of the "Journal of Hand Surgery, "Jackson, Porrino, Tan, and Daluiski ${ }^{34}$ (2003) examined the accuracy of references, dividing 
them into six bibliographic elements, viz. author name(s), title, journal name, publication year, volume number, and page number(s). In 1995, $11 \%$ of total references verified, consisted one or more inaccuracies while comparing with $30 \%$ in 1985 . Similar error rates were investigated in other journal studies in the biomedical field.

Mohta and Mohta $^{35}$ (2003) showed a very high error rate in the citations in the "Indian Journal of Surgery." They examined 203 references out of 208 references using various sources, and found a total of 276 errors. Only $34(16.7 \%)$ references were found accurate. Total $97(47.78 \%), 50$ (24.6\%), $15(7.38 \%)$, and 7 $(3.44 \%)$ references consisted inaccuracies in a single element, in two elements, in three elements and in four elements, respectively. No references were detected with an error in all the elements. Most of the mistakes were traced in the author's names. The first author's name was inaccurate in 38 references. There were no authors cited in three citations. Other authors' names had 73 inaccuracies and a wrong number of authors were detected in 24 cases. Few citations contained an error both in the first author's name and in other authors' names. Maximum number of errors in page number happened in not giving the last page number of the paper.

Boya, Ozcan, Mete, and Günal ${ }^{36}$ (2008) evaluated citation errors from randomly selected 300 references (100 references each journal) appended in "Journal of Hand Surgery" (Amer. Vol.), "Journal of Hand Surgery" (Br. and Euro. Vol.), and "British Journal of Plastic Surgery," published from 1998 to 2002. A total of $44(14.6 \%)$ references consisted errors.

Prakash Adhikari ${ }^{37}$ (2010) again conducted another study to investigate the accuracy of 63 randomly selected references appended in papers published in the two different issues of "Indian Journal of Otolaryngology and Head \& Neck Surgery” (IJOHNS), viz. December 2009, Vol. 61 No. 4 and January 2010, Vol. 62 No. 1. By splitting up references into 6 components, they were verified pin-pointedly, and compared with the original sources for accuracy. The references, which cited in the indexing journals, were considered for verification. About 70\% references in IJOHNS were accurate, while rests $(30 \%)$ were inaccurate. Errors in author's name were found in $11.1 \%$ references, whereas errors in journal's name were accounted in $6.3 \%$ of references.

Awrey et al. ${ }^{38}$ (2011) did an analysis in which, one issue from each journal was randomly selected from five general surgery journals during the year 2007 with different impact factors. From each issue 180 references were randomly selected for verification. Three reviewers examined the selected references for primary, citation, and quotation errors. The impact factors of the five journals were equated to the quantity of errors observed. The total errors per journal varied from $31.3 \%$ to $39.3 \%$, with a total of $35.4 \%$ of all references verified, consisting any variety of error. The maximum errors type observed was wrong citation of the primary source supporting a statement, the occurrence of which varied from $13.8 \%$ to $25.2 \%$, depending on the journal, and making up $53.6 \%$ of the total errors detected. The correlation between reference error rate and impact factor was not found.

Armstrong, Conduff, III, Fenton, and Coelho ${ }^{39}$ (2018) recently published an article entitled "Reference errors in otolaryngology-head and neck surgery literature" in "Otolaryngology-Head and Neck Surgery" (OHNS) journal. They also compared the findings with the results from 1997 papers. The primary aim of this research was to measure the frequency of reference and quotation errors in 8 leading journals in the field of otolaryngology-head and neck surgery. A sample of 50 references was randomly chosen from the first appeared issue in 2017 of all 8 journals (total 400 references) and was analysed for reference and quotation errors. In this study, reference errors were classified in 3 categories, namely- minor, intermediate, and major; and quotation errors in 2 categories, namely- minor and major. A total of $17 \%$ references were erroneous, in which $34 \%$ categorized as major errors. Quotation inaccuracies observed in 9\% references, in which 69\% were major errors. Authors, editors, and reviewers are responsible for reference and quotation errors and they all need to further decrease the error rates to maintain the integrity of OHNS literature.

\subsection{Paediatric Literature}

According to Oermann, Cummings, and Wilmes ${ }^{40}$ (2001), wrong citations block the retrieval of information sources. Any kind of errors in references may prevent researcher scholars from checking "all of the work by an author, and may result in authors not getting credit for their work." ${ }^{40}$ They determined the quantity and types of inaccuracies in citations in four highly used paediatric nursing periodicals. Of the 190 citations checked, 79 had an error, with the total error rate of $41.6 \%$. Major and minor errors occurred in $28.9 \%$ and $13.7 \%$ of the references, respectively. The most common type of errors was errors in the titles of articles, books, and chapters, followed by errors in the name of authors. 
Determining reference accuracy through PUBMED database, Celayir, Sander, and Celayir ${ }^{41}$ (2003) carried out a study of cited references appended in first issues of three paediatric journals, namely- "Journal of Pediatric Surgery" (Volume 36), "Pediatric Surgery International" (Volume 17), and "European Journal of Pediatric Surgery" (Volume 11) published in 2001. Non-journal references, for instance- books, conference papers, newspaper articles, indexing and abstracting sources, etc. were not included in the analysis. All references were checked thoroughly by splitting them into six bibliographic elements and matched with the records available in PUBMED database. The total citation error rate was $33.7 \%$. Specific journals' error rates were 32.1\%, 37.9\%, 34.6\% in "Journal of Pediatric Surgery," "Pediatric Surgery International," and "European Journal of Pediatric Surgery," respectively. Totally seventy percent references had inaccuracies in at least one element, and 30\% references consisted inaccuracies in two elements, while no reference had inaccuracies in three or more elements. The authors' surnames and initials $(56.2 \%)$ were the most common errors.

Gupta, Yadav, Mohta, and Choudhury ${ }^{42}$ (2005) determined the reference and quotation accuracy in volume 39 of "Indian Pediatrics" journal published in 2002. They verified 176 references out of 322 cited in 17 original papers, and found that $69(39.2 \%)$ references had citation errors, while $15(8.6 \%)$ references contained quotation errors. The maximum errors were detected in the authors' name and the article titles. They recommended that the authors who contribute in journals should verify the references' accuracy cited in their article's manuscript and make serious efforts in compiling their references.

Vargas-Origel, Gomez-Martinez, and Vargas-Nieto ${ }^{43}$ (2001) investigated the citation errors rate (29.7\%) of following paediatric journals (excluding supplements) "Acta Paediatrica," "Archives of Disease in Childhood," "Journal of Pediatrics," and "Pediatrics" published in 1999. Individual error rates were found in "Acta Paediatrica," "Archives of Disease in Childhood," "Journal of Pediatrics," and "Pediatrics" as 36\%, $22 \%, 29 \%$, and $32 \%$ respectively.

\subsection{Gynaecology Literature}

Roach, Lau, and Ngan Kee ${ }^{44}$ (1997) study has revealed error rate ranged from $56 \%$ to $67 \%$ in obstetrics and gynaecology literature. Roach and his associates examined the references in all issues (supplements excluded) published in 1995 in "American Journal of Obstetrics and Gynecology," "Australian and New Zealand Journal of Obstetrics and Gynaecology," and "British Journal of Obstetrics and Gynaecology." Errors were presented in the majority of references. The minimum error rate was $55.6 \%$ in "Australian and New Zealand Journal of Obstetrics and Gynaecology", and the maximum was $66.7 \%$ in "British Journal of Obstetrics and Gynaecology."

\subsection{Ophthalmic Literature}

Buchan, Norris, and Kuper ${ }^{45}$ (2005) examined the occurrence of quotation and reference errors in the 10 ophthalmic journals by selecting 200 cited references ( 20 references from each journal). Thirty five reference errors $(17.5 \%)$ were investigated in 32 references.

Oren and Watson ${ }^{46}$ (2009) checked the accuracy of 800 references, choosing 100 references from each journal, in the eight peer-reviewed ophthalmic journals published in 2004, in which six journals were from ophthalmology field and two were from optometry. They observed 8 types of citation errors.

\subsection{Burns Journal}

According to Al-Benna, Rajgarhia, Ahmed, and Sheikh ${ }^{47}$ (2009), a significant quantity of reference and quotation inaccuracies still exist in "Burns" journal. Wrong spelling of name of authors and partial exclusions of title of articles were the two major inaccuracies. The current findings serve as an alarm to authors, peer reviewers and editors for more attention of reference accuracy when struggling for their general aim of academic perfection and supremacy.

\subsection{Urology Journals}

Trost and Mulhall ${ }^{48}$ (2014) conducted a reference accuracy study to determine the types and frequency of citation errors exist in peer-reviewed urology journals having high-impact impact which published in 2013. Two research papers (i.e. original research or meta-analytic studies) each were chosen from latest issue of the four journals- namely, "BJU International," "European Urology," “Journal of Sexual Medicine, ” and "Journal of Urology. " Four hundred sixty eight references were checked appended in 8 research papers, out of which 142 
$(30.3 \%)$ errors were detected. One key concluding remark was "citations errors are common among high impact-factor urology journals" 48 (Trost \& Mulhall, 2014, p. e330).

\subsection{Orthopaedic Journals}

Davids, Weigl, Edmonds, and Blackhurst ${ }^{49}$ (2010) assessed the quotations accuracy and verified 200 randomly selected citations from twenty research papers appeared in four peer-reviewed orthopaedic journals. Fifty one references contained errors. The total citation error rate was " $26 \%$ with a $95 \%$ confidence interval of $16.5 \%$ to $37.3 \%$. The median citation error rate per journal was $27 \%$ (range, $10 \%$ to $38 \%$ )." ${ }^{49}$ Buijze, Weening, Poolman, Bhandari, and Ring ${ }^{50}$ (2012) noted that "inaccurate quotations can propagate misleading information, which might affect the management of patients" ${ }^{, 50}$ (p. 276).

\section{Reference Accuracy in Doctoral Theses}

Wrong citations mistrust in the accuracy of a research, create dilemma, wastage of time and unwanted "financial charges for information centres, libraries and researchers" objective of Azadeh and Vaez's (2013) research was to determine the reference accuracy of journal articles in doctoral theses in Farsi. These doctoral theses were awarded by the Tehran and Tabriz based two Universities of Medical Sciences during 2007-2008. The level of accuracy of references was not satisfactory in both the medical universities. They checked a sum of 704 journal articles' references, in which 357 references were from the Tehran and 347 from the Tabriz. Total 53\% of journal articles' references in the Tabriz and $62 \%$ in the Tehran contained errors. In the Tabriz 136 references and in the Tehran 164 references were totally accurate. Thirty four references $(9.8 \%)$ out of 357 in the Tehran were compiled according to the Vancouver referencing style. According to Azadeh and Vaez (2013), "accuracy of referencing did not differ significantly between the two groups, but compliance with the Vancouver style was significantly better in the Tehran" ${ }^{, 51}$ (p. 232).

\section{Reference Errors in PubMed Database}

Mitchell S. Cappell ${ }^{52}$ (2016) detected major bibliographic errors in PubMed database. Cappell reviewed his 240 articles cited in PubMed during 1982 to 2015 and found 3 major bibliographic errors (1.25\% error rate). The PubMed is a ubiquitous bibliographic database of biomedical research journals and literature search engine. It doesn't contain full texts articles, but provides a digital card catalogue. According to Cappell (2016), major bibliographic "errors in PubMed could render articles inaccessible to researchers or clinicians performing computerized literature searches" important than errors in any specific journal.

Due to reference inaccuracies, indexing of journals as well as authors in citation databases becomes difficult $^{53}$ (Garfield, 1990). Eugene Garfield (1991) stressed that "acknowledging prior research and intellectual debts is of crucial ethical importance" ${ }^{, 54}$ and invoked for the necessity preventively to teach young scholars on the research ethics incorporated in entire referencing (p. 14).

\section{Reference Accuracy and Peer Review}

The reference accuracy makes the scholarly communication more reliable as well as useful, and leads towards the high quality scholarship ${ }^{29}$ (Asano, Mikawa, Nishina, Maekawa, \& Obara, 1995a). The reference errors of the "Canadian Journal of Anaesthesia" were reduced by 50\% from 1990 to 1994 by demanding the photocopy of the first page of each and every reference cited in the "Reference lists'30 (Asano, Mikawa, Nishina, Maekawa, \& Obara, 1995b). When a scientific article contains erroneous references, "the overall quality of the research paper and also the editors of the journal, which published the paper, are questioned"55 (Gupta, 2017b, p. 182).

Foreman and Kirchhoff (1987) revealed that cited references "provide a method of evaluating the article; [and] assist in assessing an author's credibility" ${ }^{\prime 56}$ (p. 177). In fact, several researchers do not check the original literary sources before using and citing them. According to an investigation, which is based on "a stochastic modeling of the citation process that explains empirical studies of misprint distributions in citations," read them. Only $20 \%$ of writers cited an article had actually read it. 


\section{Conclusion}

A list of references in a scientific article provides details of information sources consulted and used directly or indirectly during the research work, and indicates that the researcher has investigated the paper's topic thoroughly. The Nobel laureate geneticist and former president of Rockefeller University, Joshua Lederberg (1993) delivered a lecture on "Communication as the Root of Scientific Progress" 58 focussing on the relevance of scholarly literature and scholarly communication for the development of science. Quality related objectives in scholarly communications can be achieved with the help of thorough and extensive peer review process $^{59}$ (Gupta, 2017c). Referencing correctly according to a given citation style guide is a prime responsibility of authors, because "it protects them from charges of academic theft and plagiarism" Babel, 2017, p. 399). Peden (1991) advised both teachers and learners as, "instructors should teach and students should learn precision in preparing reference lists" ${ }^{\prime 61}$ (p. 103).

Peer-reviewed journals, which are being indexed in international citation databases and possess high impact factor, have reference errors. Frank Place, Jr., (1916) critically pointed out that "many esteemed scholars take a reference from another's bibliography as though it was thereby Gospel truth itself",62 (p. 699). Being perfect, needless to say, is the ultimate quality. A scholarly communication in the form of research article, as a high profile academic publication, is deemed to be error free reference list while errors in references are intractable problems. When any scholarly article contains faulty citations, the whole quality of the research work embodied in journal publication becomes questionable.

Source of Funding: No external funding was received in support for conducting this study.

\section{References}

[1]. Borgman, C.L. (1990). Editor's introduction, in Borgman, C.L. (Ed.), Scholarly Communication and Bibliometrics, Sage Publications: Newbury Park, CA, pp. 10-27.

[2]. Gupta, V. K. (2018). Citation errors in 'Libres: Library and Information Science Research e-Journal.' Indian Journal of Library and Information Science: An International Journal, 12(1), 42-49. DOI: 10.21088/ijlis.0973.9548.12118.6

[3]. Pandit, I. (1993). Citation errors in library literature: A study of five library science journals. Library \& Information Science Research, 15(2), 185-198.

[4]. Yankauer, A. (1990). The accuracy of medical journal references. CBE Views, 13(2), 38-42.

[5]. Doms, C. A. (1989). A survey of reference accuracy in five national dental journals, Journal of Dental Research, 68(3), 442-444.

[6]. Gupta, V. K. (2017a). Citation errors in scholarly communication: A critical evaluation. Indian Journal of Library and Information Science: An International Journal, 11(2), 228-233. DOI: http//dx.doi.org/10.21088/ijlis.0973.9548.11217.20

[7]. Spivey, C. A., \& Wilks, S. E. (2004). Reference list accuracy in social work journals. Research on Social Work Practice, 14(4), 281-286. DOI: 10.1177/1049731503262131

[8]. Faunce, G. J., \& Job, R. F. S. (2001). The accuracy of reference lists in five experimental psychology journals. American Psychologist, 56(10), 829-830. DOI: 10.1037//0003-066X.56.10.829

[9]. Onwuegbuzie, A. J., Frels, R. K., \& Slate, J. R. (2010). Editorial: Evidence-based guidelines for avoiding the most prevalent and serious APA error in journal article submissions- the citation error. Research in the Schools, 17(2), 1-24.

[10]. Gasparyan, A. Y., Yessirkepov, M., Voronov, A. A., Gerasimov, A. N., Kostyukova, E. I., \& Kitas, G. D. (2015). Preserving the integrity of citations and references by all stakeholders of science communication. Journal of the Korean Medical Sciences, 30(11), 1545-1552. DOI: http://dx.doi.org/10.3346/jkms.2015.30.11.1545

[11]. Goodrich, J. E., \& Roland, C. G. (1977). Accuracy of published medical reference citations. Journal of Technical Writing and Communication, 7(1), 15-19. DOI: 10.2190/2B2A-F34L-0TXG-WNQ7

[12]. De Lacey, G., Record, C., \& Wade, J. (1985). How accurate are quotations and references in medical journals? British Medical Journal, 291(6499), 884-886. Retrieved from: http://www.ncbi.nlm.nih.gov/pmc/articles/PMC1416756/pdf/bmjcred00467-0046.pdf

[13]. Evans, J. T, Nadjari, H. I., \& Burchell, S. A. (1990). Quotational and reference accuracy in surgical journals: A continuing peer review problem. Journal of the American Medical Association, 263(10), 1353-1354. DOI: 10.1001/jama.1990.03440100059009

[14]. Ngan Kee, W. D., Roach, V. J., \& Lau, T. K. (1997a). The accuracy of references in the Hong Kong Medical Journal. Hong Kong Medical Journal, 3(4), 377-380.

[15]. Adhikari, P. (2009). Accuracy of references in indexed journals of Nepal. Nepal Medical College Journal, 11(2), 130-132.

[16]. Samad, A., Khanzada, T. W., Kumar, B., \& Malik, K. A. (2013). Accuracy of references: Comparison between two premier Pakistani medical journals. Journal of Pakistan Medical Association, 63(4), 445-447. 
[17]. International Committee of Medical Journal Editors (ICMJE). (2017). Recommendations for the conduct, reporting, editing, and publication of scholarly work in medical journals. Retrieved from: http://www.icmje.org/icmje-recommendations

[18]. Eichorn, P., \& Yankauer, A. (1987). Do authors check their references? A survey of accuracy of references in three public health journals. American Journal of Public Health, 77(8), 1011-1012.

[19]. Key, J. D., \& Roland, C. G. (1977). Reference accuracy in articles accepted for publication in the Archives of Physical Medicine and Rehabilitation. Archives of Physical Medicine \& Rehabilitation, 58(3), 136-137.

[20]. Goldberg, R. et al. (1993). Reference accuracy in the emergency medicine literature. Annals of Emergency Medicine: An International Journal, 22(9), 1450-1454. DOI: http://doi.org/10.1016/S0196-0644(05)81995-X

[21]. Raja, U. Y., \& Cooper, J. G. (2006). How accurate are the references in Emergency Medical Journal? Emergency Medical Journal, 23(8), 625-626.

[22]. O’Connor, A. E., Lukin, W., Eriksson, L., \& O'Connor, C. (2013). Improvement in the accuracy of references in the journal Emergency Medicine Australasia. Emergency Medicine Australasia, 25(1), 64-67. DOI: $10.1111 / 1742-6723.12030$

[23]. George, P. M., \& Robbins, K. (1994). Reference accuracy in the dermatologic literature. Journal of the American Academy of Dermatology, 31(1), 61-64. DOI: http://dx.doi.org/10.1016/S0190-9622(94)70136-9

[24]. Singh, S., \& Chaudhary, R. (2009). Accuracy of references cited in articles published in Indian journal of dermatology, Venereology and Leprology: A pilot study. Indian Journal of Dermatology, Venereology and Leprology, 75(5), 488-491. DOI: 10.4103/0378-6323.55392

[25]. Gosling, C. M., Cameron, M., \& Gibbons, P. F. (2004). Referencing and quotation accuracy in four manual therapy journals. Manual Therapy, 9(1), 36-40. DOI: http://dx.doi.org/10.1016/S1356-689X(03)00056-0

[26]. Unver, B., Senduran, M., Kocak, F. U., Gunal, I., \& Karatosun, V. (2009). Reference accuracy in four rehabilitation journals. Clinical Rehabilitation, 23(8), 741-745. DOI: 10.1177/0269215508102968

[27]. Aronsky, D., Ransom, J., \& Robinson, K. (2005). Accuracy of references in five biomedical informatics journals. Journal of the American Medical Informatics Association, 12(2), 225-228. DOI: 10.1197/jamia.M1683

[28]. McLellan, M. F., Case, L. D., \& Barnett, M. C. (1992). Trust, but verify. The accuracy of references in four anesthesia journals. Anesthesiology, 77(1), 185-188.

[29]. Asano, M., Mikawa, K., Nishina, K., Maekawa, N., \& Obara, H. (1995a). The accuracy of references in Anaesthesia. Anaesthesia: Journal of the Association of Anaesthetists of Great Britain and Ireland 50(12): 1080-1082.

[30]. Asano, M., Mikawa, K., Nishina, K., Maekawa, N., \& Obara, H. (1995b). Improvement of the accuracy of references in the Canadian Journal of Anaesthesia. Canadian Journal of Anaesthesia 42(5): 370-372.

[31]. Orlin, W., Pehling, J., \& Pogrel, M. A. (1996). Do authors check their references? A survey of 500 references from the Journal of Oral and Maxillofacial Surgery. Journal of Oral Maxillofacial Surgery, 54(2), 200-202.

[32]. Ngan Kee, W. D., Roach, V. J., \& Lau, T. K. (1997b). How accurate are references in the Australian and New Zealand Journal of Surgery? Australian and New Zealand Journal of Surgery, 67(7), 417-419.

[33]. Fenton, J., Brazier, H., Souza, A., Hughes, J., \& McShane, D. (2000). The accuracy of citation and quotation in otolaryngology/head and neck surgery journals. Clinical Otolaryngology, 25(1), 40-44. DOI: 10.1046/j.1365-2273.2000.00322.x

[34]. Jackson, K., Porrino, J. A. Jr., Tan, V., \& Daluiski, A. (2003). Reference accuracy in the Journal of Hand Surgery. Journal of Hand Surgery, 28(3), 377-380. DOI: http://doi.org/10.1053/jhsu.2003.50085

[35]. Mohta, A., \& Mohta, M. (2003). Accuracy of references in Indian Journal of Surgery. Indian Journal of Surgery, 65(2), 156-158.

[36]. Boya, H., Ozcan, O., Mete, A. M., \& Günal, I. (2008). Accuracy of references in journals of hand surgery. Journal of Scholarly Publishing, 39(2), 174-180. DOI:https://doi.org/10.1353/scp.2008.0008

[37]. Adhikari, P. (2010). Accuracy of references in Indian Journal of Otolaryngology and Head \& Neck Surgery. Indian Journal of Otolaryngology and Head \& Neck Surgery, 62(4), 338-341. DOI: 10.1007/s12070-0100048-y

[38]. Awrey, J., Inaba, K., Barmparas, G., Recinos, G., Teixeira, P. G. R., Chan, L. S., Talving, P., \& Demetriades, D. (2011). Reference accuracy in the general surgery literature. World Journal of Surgery, 35(3), 475-479. DOI: 10.1007/s00268-010-0912-7

[39]. Armstrong, M. F., Conduff, III, J.H., Fenton, J. E., \& Coelho, D. H. (2018). Reference errors in otolaryngology-head and neck surgery literature. Otolaryngology-Head and Neck Surgery, 159(2), 249-253. DOI: $10.1177 / 0194599818772521$

[40]. Oermann, M. H., Cummings, S. L., \& Wilmes, N. A. (2001). Accuracy of references in four pediatric nursing journals. Journal of Pediatric Nursing, 16(4), 263-268. DOI: http://dx.doi.org/10.1053/jpdn.2001.25537

[41]. Celayir, A. C., Sander, S., \& Celayir, S. (2003). Accuracy of references in the pediatric surgery journals. Journal of Pediatric Surgery, 38(4), 653-654.

[42]. Gupta, P., Yadav, M., Mohta, A., \& Choudhury, P. (2005). References in Indian pediatrics: Authors need to be accurate. Indian Pediatrics, 42(2), 140-145.

[43]. Vargas-Origel, A., Gomez-Martinez, G., \& Vargas-Nieto, M. A. (2001). The accuracy of references in paediatric journals. Archives of Disease in Childhood, 85(6), 497-498. DOI: 10.1136/adc.85.6.497

[44]. Roach, V. J., Lau, T. K., \& Ngan Kee, W. D. (1997). The quality of citations in major international obstetrics and gynecology journals. American Journal of Obstetrics and Gynecology, 177(4), 973-975. DOI: http://dx.doi.org/10.1016/S0002-9378(97)70303-X 
[45]. Buchan, J. C., Norris, J., \& Kuper, H. (2005). Accuracy of referencing in the ophthalmic literature. American Journal of Ophthalmology, 140(6), 1146-1148.

[46]. Oren, G., \& Watson, M. (2009). Accuracy of references in the ophthalmic literature. Journal of the Medical Library Association, 97(2), 142-145.

[47]. Al-Benna, S., Rajgarhia, P., Ahmed, S., \& Sheikh, Z. (2009). Accuracy of references in burns journals. Burns, 35(5), 677-680. DOI: http://dx.doi.org/10.1016/j.burns.2008.11.014

[48]. Trost, L., \& Mulhall, J. P. (2014). Frequency of citation errors among male sexual medicine publications in high-impact urology journals. Journal of Urology, 191(4S), e330-e331.

[49]. Davids, J. R., Weigl, D. M., Edmonds, J. P., \& Blackhurst, D. W. (2010). Reference accuracy in peerreviewed pediatric orthopaedic literature. Journal of Bone and Joint Surgery America, 92-A(5), 1155-1161. DOI: $10.2106 / J B J S . I .00063$

[50]. Buijze, G. A., Weening, A. A., Poolman, R. W., Bhandari, M., \& Ring, D. (2012). Predictors of the accuracy of quotation of references in peer-reviewed orthopaedic literature in relation to publications on the scaphoid. Journal of Bone and Joint Surgery [Br], 94(2), 276-280. DOI: 10.1302/0301-620X.94B2.27618.

[51]. Azadeh, F., \& Vaez, R. (2013). The accuracy of references in $\mathrm{PhD}$ theses: A case study. Health Information and Libraries Journal, 30(3), 232-240.

[52]. Cappell, M. S. (2016). Major bibliographic errors in PubMed: Personal experience among 240 publications and proposed remediation process for errors. Journal of the Medical Library Association, 104(1), 83-84. DOI: http://dx.doi.org/10.3163/1536-5050.104.1.015

[53]. Garfield, E. (1990). Journal editors awaken to the impact of citation errors. How we control them at ISI. Current Comments, 13(41), 367-375. Retrieved from http://www.garfield.library.upenn.edu/essays/v13p367y1990.pdf

[54]. Garfield, E. (1991). Bibliographic negligence: A serious transgression. Scientist, 5(23), 14.

[55]. Gupta, V. K. (2017b). Accuracy of references in two Indian library and information science journals. Annals of Library and Information Studies, 64(3), 181-189. Retrieved from: http://nopr.niscair.res.in/bitstream/123456789/42986/1/ALIS\%2064\%283\%29\%20181-189.pdf

[56]. Foreman, M. D., \& Kirchhoff, K. T. (1987). Accuracy of references in nursing journals. Research in Nursing and Health, 10(3), 177-183.

[57]. Simkin, M. V., \& Roychowdhury, V. P. (2003). Read before you cite! Complex Systems, 14(3), 269-274.

[58]. Lederberg, J. (1993). Communication as the root of scientific progress. Current Contents 1: 5-11.

[59]. Gupta, V. K. (2017c). Quality control through peer review process in scholarly communication: Review of related literature. IRA- International Journal of Management and Social Sciences, 8(3), 248-255. DOI: http://dx.doi.org/10.21013/jmss.v8.n3.p3

[60]. Gupta, V. K., \& Babel, P. (2017). Dimensions of reference accuracy and citation errors. Indian Journal of Library and Information Science: An International Journal, 11(3), 394-400. DOI: http//dx.doi.org/10.21088/ijlis.0973.9548.11317.17

[61]. Peden, B. F. (1991). Teaching the importance of accuracy in preparing references. Teaching of Psychology, $18(2), 102-105$.

[62]. Place, F. Jr. (1916). Verify your references. A word to medical writers. New York Medical Journal, 104(15), 697-699.

\section{About the Authors}

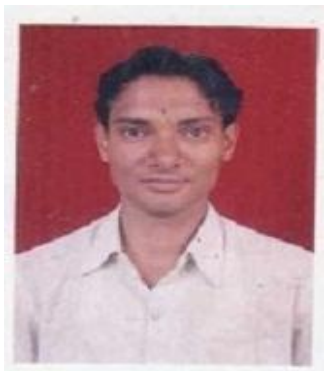

Vishnu Kumar Gupta, presently working as Assistant Professor in Department of Library and Information Science, University of Rajasthan, Jaipur and is research fellow in the Department of Library and Information Science in the Banasthali University, Rajasthan (India). He received his MLIS from University of Rajasthan, Jaipur in 2002; scored highest marks in India in UGC's National Eligibility Test; and has extensive experience managing distinguished information services in college and university libraries. Orcid: http://orcid.org/0000-0003-4579-7132 